\title{
Ergonomic Risk By: Repetitive Movements, in the Operators of a Crude Oil Production Plant
}

\author{
Guillermo Neusa Arenas ${ }^{1 *}$, Jeanette del Pilar Ureña Aguirre², Ramiro \\ Vicente Saraguro ${ }^{3}$ and Edwin Javier Iza Sánchez ${ }^{4}$ \\ ${ }^{1}$ Occupational Health Specialist, UTN-Ecuador \\ ${ }^{2}$ Magister in Industrial and Environmental Safety and Hygiene, UTN-Ecuador \\ ${ }^{3}$ Master in in Business Administration, UTN-Ecuador \\ ${ }^{4}$ Industrial Engineer, UTN-Ecuador
}

Research Article

Volume 4 Issue 4

Received Date: June 01, 2020

Published Date: July 02, 2020

DOI: $10.23880 /$ eoij-16000245

*Corresponding author: Guillermo Neusa Arenas, Occupational Health Specialist, Universidad Técnica del Norte, IbarraEcuador, postal code: 100105, Ibarra, Ecuador, Email: gneusa@utn.edu.ec; Tel: (+00593) (9) (84942409)

\section{Abstract}

Hobbies to health due to exposure to repetitive physical effort in operators of crude production plants and, in each of the different macro processes by work cycles they carry out in their daily tasks, lead to different biomechanical movements in the body, creating occupational pathological hobbies such as musculoskeletal disorder (SMD). In a study carried out through the calculation of the (finite) sample of 150 operators and, based on the Nordic Standardized Questionnaire (CNE), several operators were assessed for exposure to the dysergonomic risk factor and; By applying the OCRA Checklist and the OCRA method, the exposure index (IE) is analyzed, which provides a result of the position with the highest IE; As a result of the data obtained by the initial checklist, it was determined, of 18 positions or areas of work analyzed, $72 \%$ are at high risk, $21 \%$ of operators, clinical lumbar clinical picture, although 20\%, have A clinical picture of painful shoulder. As an effect, the execution of an occupational ergonomics plan allows the establishment of preventive measures for pathological control by postural biometrics, creating a safe environment and protection of the health of the operators.

Keywords: Pathology; Biomechanics; Musculoskeletal Disorder; Biometrics

\section{Introduction}

MSDs can be caused by different factors (combination of over-stressing factors), these include also those physical factors (by exposure to biomechanical load applied to the musculoskeletal tissues that can cause MSDs). However, there are factors that can degenerate in the short, medium and long term in organizational and psychosocial settings. As the elements or risk factors occur, they can affect workers' health, as it is related to the various contextual and anatomical dimensions of the body, such as in the organization of the area or workplace, as well as sociodemographic and individual factors [1].

As for the etiological dysergonomic factors for these disorders, their knowledge is not recent, since it begins to be known in 1700, when the father of occupational medicine, Bernardino Ramazzini, indicated that the pains in the upper limbs were related to "being in many occasions constantly seated, the movement of the hand or at the same time, the attention and demand in the mental work", as he indicated in his work "De Morbis Artificum Diatriba" on the (Treaty on the diseases of the workers) [2]. On the other hand, the movement of the trunk allows for both lateral and rotational flexions. When determining a lifting of loads, these osteomuscular or biomechanical movements must be limited, in order to control the increase of force on the lumbar discs; "when the pressure is previously multiplied according to the degree of flexion of the trunk" [3]. The partial or total failure to comply with the measures or technical parameters, 
as well as preventive control actions in ergonomics and health by the worker and/or the organization, may lead to different pathological injuries in the worker or to damages that may disturb the productive macro-processes. "Those directly related to the manual handling of loads can be summarized in two fundamental axes, on the one hand, the risks of exposure by work cycles; as a second part, the consequences on the worker, in the short and medium term, create an occupational clinical picture [4]. Biomechanics considers both external and internal forces. In external forces, such as the load, they are alien to the structure, that is, to the body's force of gravity, since, at the moment of exercising resistance to air, as well as inertia, water resistance, floor reaction and muscular action, they form a single tension. While the internal forces, are determined by the osteomuscular tensions, which, to the action of the body establishes an action and movement of the load [5]. However, the dysergonomic risks are factors of discordance between the human-machine system, starting in the design of the work place, location of machinery, construction, operation, knowledge, ability, which can contribute to the conditions and characteristics in the workers, causing interrelations in their work environment as well as in the work environment as; fatigue, repetitive movements, bad postures, monotony or physical overload".

At the same time, dysergonomic risk factors are a set of task activities per work cycle; the area or job may influence the increase in the probability that a worker may be exposed to them, developing a clinical occupational picture or injury in their work. These can be related to overexertion, manual handling of loads, forced postures or repetitive movements. However, forced postures by risk factor are determined by the frequency of movements, trunk postures, neck postures, duration of posture, upper limb postures and lower limb postures. Meanwhile, repetitive movements are a risk factor due to: the use of force, the adoption of postures, the frequency of movements, forced movements and movement times per work cycle, which, upon recovery, influence the duration of repetitive work.

In studies carried out, the manual handling of loads by risk factor, is executed depending on whether the push and pull, the lifting of the load, transport or the weight of the load, is determined according to the distance of the load, posture, strength and duration of the task, causing unfavourable health conditions. The most frequent injuries caused by Disergonomic risks are: tendinitis, carpal tunnel syndrome, bursitis, hernia, trigger finger, cervical tension syndrome, among others [6].

\section{Materials and Methods}

At the starting point of any research to estimate the identification of risk factors in a population of workers, several methodological stages must be taken into account; Firstly, the areas and their productive macro processes are analysed; Secondly, the number of workers to be evaluated based on the sample calculation (finite) and, Thirdly, the methodology applied to assess the exposure of workers according to the work cycles. "In the general risk assessment, the most important aspects to be considered in each of the stages mentioned are indicated [7].

\section{Subjective Representation by Survey}

The technique of the Standardized Nordic Questionnaire (SQN) [8], which determines the MSDs in each of the operators from the outset, allows the results to be obtained and evaluated quickly and effectively. The analysis of the $\mathrm{CNE}$ was carried out by professionals and researchers in the field of ergonomics with the support of students from the industrial engineering career, UTN, trained in the subject of Ergonomics and qualified with 120 hours of theoretical and practical academic learning, coordinated by the Director of the research project. The questions were related under a dialogic context that allows the validity in each one of the consultations made to the operators, which agreed to affirm the semantic effectiveness. However, for the analysis of each of the data, the refinery's macro-processes were taken into account (Figure 1.) for each production area, while in Table 1, the areas and personnel to be evaluated are defined.

\begin{tabular}{|c|c|}
\hline AREAS / PUESTO & No. Operators \\
\hline Warehouse technicians & 4 \\
\hline Generation operator & 10 \\
\hline API Welding Assistant & 6 \\
\hline Instrumentation and control technician & 16 \\
\hline Technical overhaul & 14 \\
\hline Maintenance Technician & 14 \\
\hline Welder & 4 \\
\hline Electrical Technician & 6 \\
\hline Automotive Maintenance Technician & 6 \\
\hline Cathodic Protection Technician & 4 \\
\hline Right-of-way assistant & 6 \\
\hline API Welder & 4 \\
\hline Crane operator & 4 \\
\hline Auxiliary service technician & 8 \\
\hline Vacuum Technician & 4 \\
\hline Laboratory Technician & 6 \\
\hline Production operator & 30 \\
\hline Camp Technician & 4 \\
\hline Total & 150 \\
\hline
\end{tabular}

Table 1: Risk Factor Identification. 


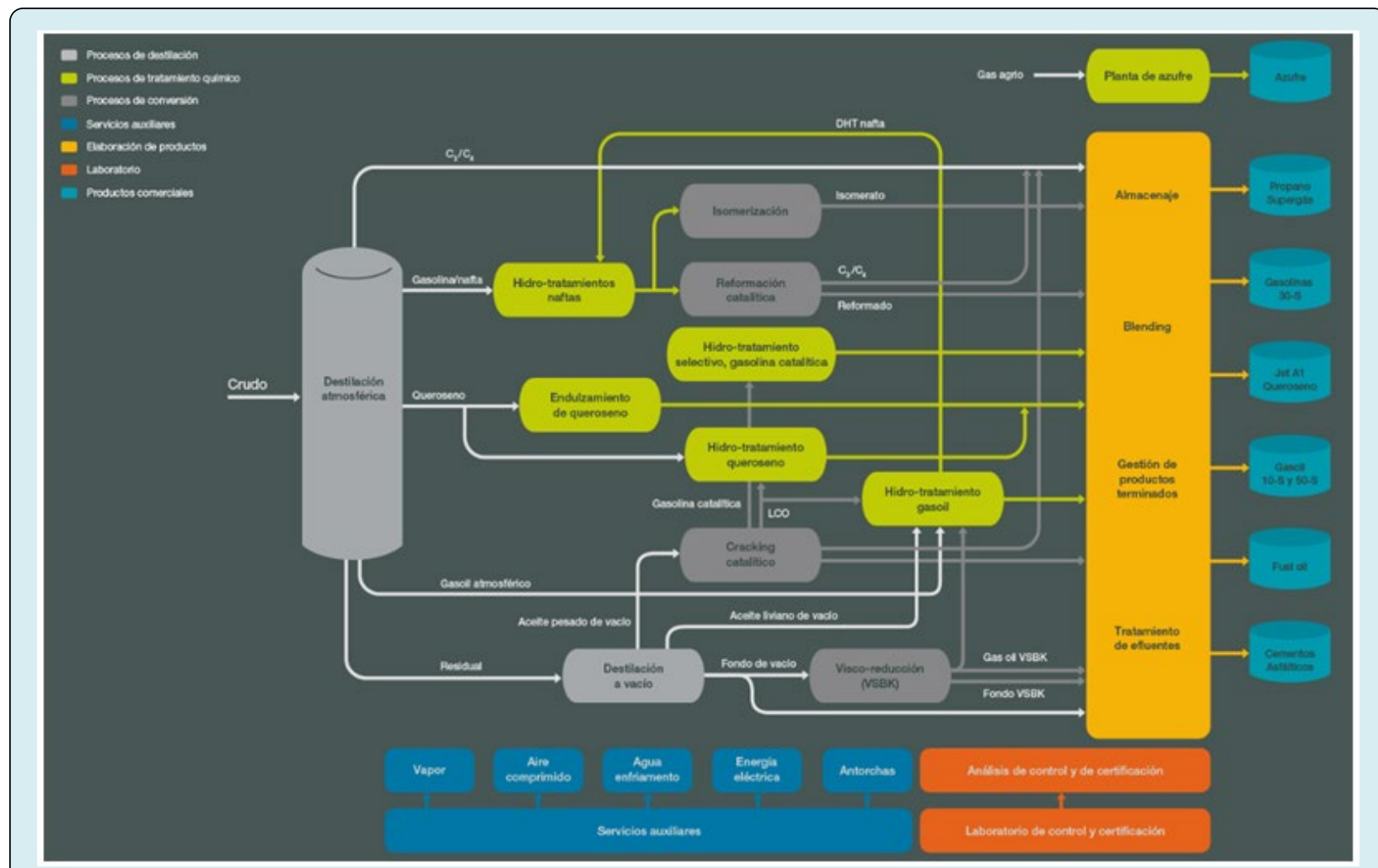

Figure 1: Macroprocesses in the crude oil production area [9].

\section{Population of Analysis}

The analysis carried out, determines the number of operators according to the areas of crude oil production, and several centers of oil production (CPF). The sample (finite), determines the method of application, as the set of elements or individuals, that, congregate the necessary typologies of study of the working population of the CPF; "which really will be carried out in study, considering a subset of the population" (Gallego, 2004). For the stages of the sample calculation, it was established according to the number of operators, with a ratio of 150 , with a margin of error of $4.0 \%$, and a reliability of $95 \%$. In Table 2 , the calculation of the finite sample is established according to the Vallejo method (Vallejo, 2012).

$$
n=\frac{N^{*} Z_{\alpha}^{2} p^{*} q}{d^{2} *(N-1)+Z_{\alpha}^{2} * p^{*} q}
$$

$\mathrm{n}=$ sample size

$\mathrm{N}=$ population size

$Z_{\alpha}^{2}=$ confidence level value

$\mathrm{p}=$ punctual estimation

$\mathrm{q}=$ probability against

\begin{tabular}{|c|c|c|c|c|c|}
\hline \multicolumn{6}{|c|}{ Sample Population Table (N) } \\
\hline \multicolumn{5}{|c|}{ margin of error } & $4,0 \%$ \\
\hline Margin of Error & $4,0 \%$ & $*$ & \multirow{4}{*}{ N.O. } & 100 & 86 \\
\hline Worker Size - Finite & 200 & & & 150 & 120 \\
\hline Confidence Level & $95 \%$ & $* *$ & & 200 & 150 \\
\hline $\mathrm{Z}$ values (confidence level value) & $90 \%$ & & & 250 & 177 \\
\hline
\end{tabular}

Table 2: Estimated number of operators for the evaluation.

When taking the result of the sample calculation $(150$ workers), in table 3 and graph 1, they are analyzed by sex and age in the areas and processes of the CPF. 


\begin{tabular}{|c|c|c|}
\hline Prom. Age & Men & Women \\
\hline $20-25$ & 18 & 11 \\
\hline $26-35$ & 28 & 9 \\
\hline $36-30$ & 37 & 0 \\
\hline $31-49$ & 36 & 2 \\
\hline $50-+$ & 9 & 0 \\
\hline Subtotal & 128 & 22 \\
\hline Total & 150 & \\
\hline
\end{tabular}

Table 3: Description of the population.

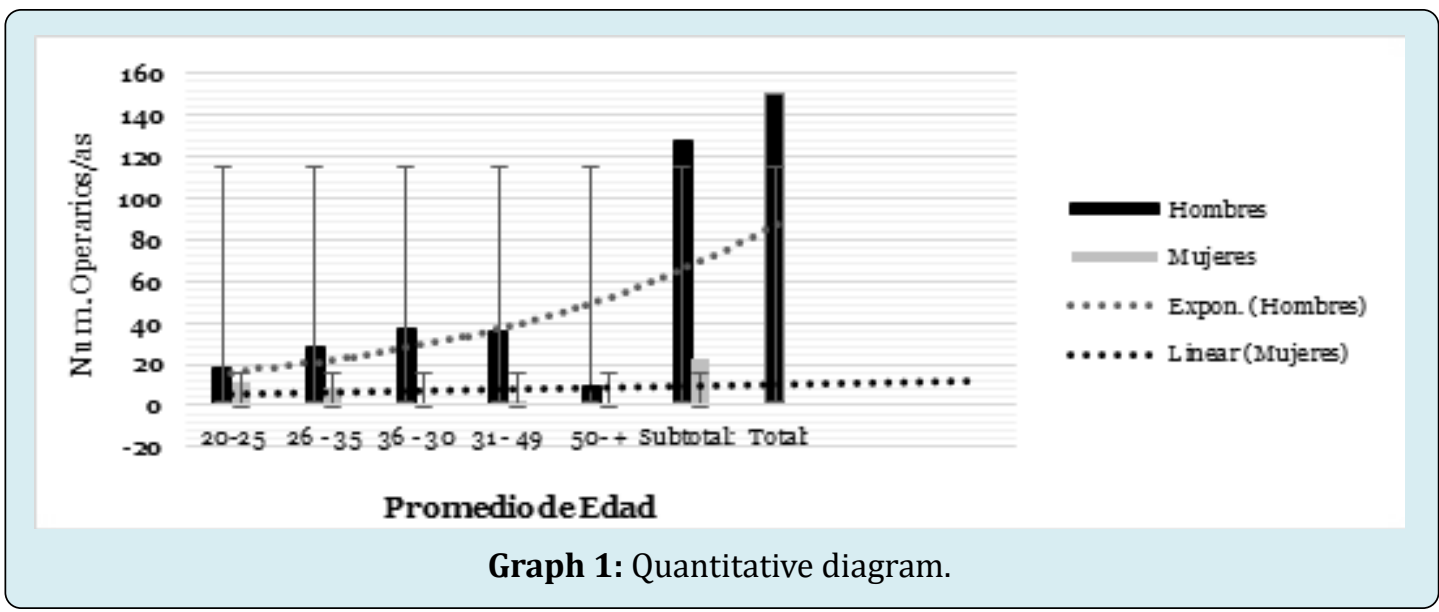

\section{Method of Evaluation by Work Cycle}

OCRA checklist as a starting tool: The OCRA method considers various aspects of identifying the risk factor for postural dysergonomic exposure, establishing a preliminary analysis, based on ISO 11228-3 [10]. The first part of the analysis, the observation and monitoring of each posture by the extremes, analyzes and identifies the factor, the strength, repetitiveness (in strength), (harmful) postures of type of movement and the long journey by work cycles that make possible an absence by recovery time in the operator.

Application in the operators: To establish a value by the Check List OCRA Index (ICKL) and identify and classify the risk factor as: optimal, acceptable, very light, light, medium or high, the use of an equation is required [11].

$$
I C K L=(F R+F F+F F z+F P+F C) * M D
$$

$\mathrm{FR}=$ For the recovery factor.

$\mathrm{FF}=\mathrm{By}$ the frequency factor.

$\mathrm{FFz}=\mathrm{By}$ the force factor.

$\mathrm{FP}=\mathrm{By}$ the posture and movement factor.

$\mathrm{FC}=$ Because of the additional risk factor.

$\mathrm{FD}=$ By the cycle time multiplier.

\section{Net Time per Cycle / Repetitive Work}

It is essential to determine the net repetitive work time (TNTR) and the network cycle time (TNC) for the operators before calculating the ICKL. The TNTR is the time during which the operator performs the repetitive activities or tasks, that is, the length of the working day at the site, less breaks, non-repetitive tasks, rest periods and other downtime [11].

$$
T N T R=D T-(T N R+P+A)
$$

DT= For the duration in minutes of the shift in a day.

TNR= For the non-repetitive working time.

$\mathrm{P}=\mathrm{By}$ the duration in minutes of the breaks while occupying the position

$A=$ For the length of the lunch break in minutes.

At the same time, the TNC, is the net time per work cycle if we only consider the repetitive tasks executed at the job under examination.

$$
T N C=60 *\left(\frac{T N T R}{N C}\right)
$$

$\mathrm{NC}=\mathrm{By}$ the number of work cycles performed at the position These TNTR and TNC calculations are derived by calculating the factor and multiplier from the ICKL equation. 
The first instance to be analyzed is, if the tasks per work cycle are performed by repetitive motion [12].

The OCRA method, 2005- Occupational Repetitive Action (OCRA) establishes a criterion for determining risk exposure and MSD associated with repetitive movements by the upper limbs [13].

Therefore, the risk factor recommended by the International Ergonomics Association (IEA) is considered by assessment: repetitiveness, due to inadequate or static postures, forced movements and forces, the lack of rest both for recovery periods, assessing along the work cycles or activity time by the worker. On the other hand, other influential factors during the task can be considered such as vibrations, which can influence the worker's condition due to exposure to cold and other factors. The following terms need to be understood: [14].

- Working time: daily work cycle in which the operator performs various tasks.

- Task: work or work activity whose operation objective is specified.

- Cycle: is the sequence of actions and techniques, to the movement both physical and mechanical of short, medina and long repetitive continuation in the same way again and again.

Exposure calculation process: For the exposure index, it corresponds to the sum of actions performed by both upper and lower limbs in repetitive tasks by cycles within the working day, indicated in the following equation: [15].

$$
I E=\frac{A_{e}}{A_{r}}
$$

$\mathrm{IE}=$ Exposure Index

$\mathrm{A}_{\mathrm{e}}=$ Existing repetitive movements in the shift

$\mathrm{A}_{\mathrm{r}}=$ Number of existing tasks

When analyzing the actions in the work area, it is not recommended to use for evaluations in the use of the $\mathrm{PVD}^{11}$. Therefore, walking or visualizing does not demand any mechanical action or cycles by the upper extremities.

To determine the calculation: A_r it is necessary to perform an analysis by means of an equation:

$$
I E=\sum_{n}\left[C F *\left(F o_{m i} * P o_{m i} * \operatorname{Re}_{m i}^{*} A d_{m i}\right) * D_{i}\right] * R c_{m}^{*} D u_{m}
$$

$n=$ For each of the cycles of tasks to be carried out, by repeated movement.
$\mathrm{CF}=$ Per constant to the frequency of operations to the task (X).

$\mathrm{Fo}_{\mathrm{mi}}=$ By the force factor in the task (X).

$\mathrm{Po}_{\mathrm{mi}}=$ By the posture factor in the task (X).

$\operatorname{Re}_{\mathrm{mi}}=$ By the repetitiveness factor in the task (X).

$\mathrm{Ad}_{\mathrm{mi}}=$ By the factor in additional elements in the task (X).

$\mathrm{D}_{\mathrm{i}}=$ By the duration in each task for repetition in minutes.

$R c_{m}=$ By the factor of the lack of period in the recovery per day.

$\mathrm{Du}_{\mathrm{m}}=\mathrm{By}$ factoring in the multiplier at the time of the function by the cycle or its usual duration in the repetitive task.

Frequency Constant (CF): In the frequency due to repetition, the risk factor is higher, consequently, the final value of the index, $\mathrm{CF}=30$ per share, per minute to the reference value is considered as a high grade variable.

Repeatability Factor ( $\left.\mathbf{R e}_{\mathrm{m}}\right)$ : In determining the OCRA methodology, other existing aspects of the same actions repeated by an average of $50 \%$ per work cycle are considered. However, when taking the times by the lesser of 15 seconds, it is by means of the multiplier to 0.70 , taking into account the multiplier by 1 .

In figure 2, it represents different aspects of the movement of postural biometry by repetition, both in the upper and lower extremities:

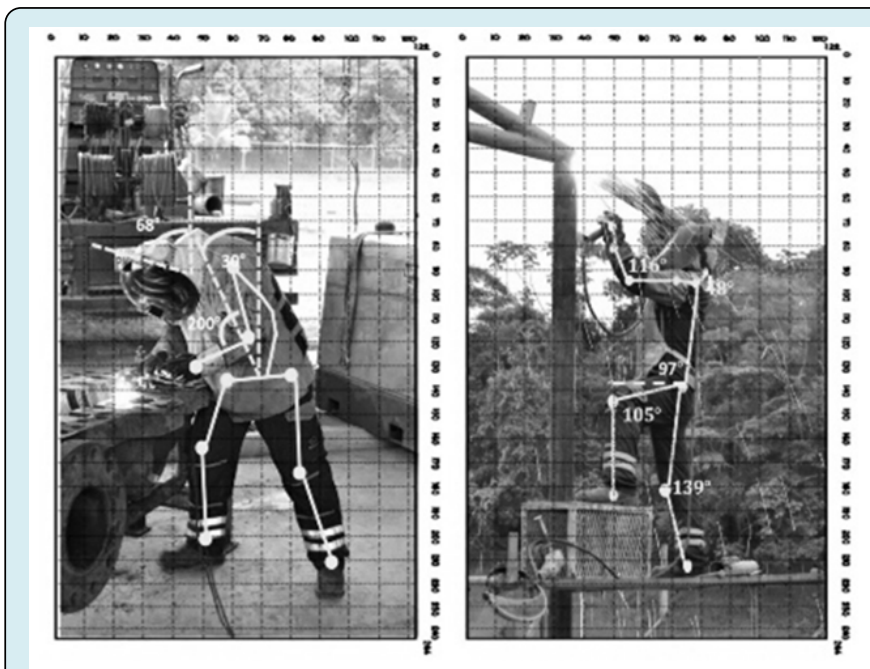

Figure 2: Postural biometry of the upper limbs.

\section{Specificity and Sensitivity}

According to studies, the OCRA index presents a high percentage with the appearance of musculoskeletal diseases of the upper limb in jobs exposed to this type of risk [15]. From the beginning, all assessments were taken to preserve

1 Display Screens 
confidentiality and study information in each of the areas and jobs in the operators evaluated. Likewise, in the cases where possible MSDs were determined, occupational physicians, ergonomists and students, who in each clinical occupational evaluation placed the operators, determined the occupational psychopathology by cycles and work times.

\section{Results}

An occupational health physician and an ergonomist participated in the Clinical Occupational Evaluation (COE). For this purpose, an estimation was formalized that included the evaluation of active and passive movements, application of a numerical scale according to the OCRA method, as a basis for pain (10), estimation by functionality, plus the clinical occupational tests. This evaluation in the work cycle of an eight-hour day with respect to the CNE study.

\section{Initial Data Frequency}

Based on the Nordic Questionnaire (NQ) of Kuorinka [8], an analysis was performed by postural biometry in each work station of the plant operators, with the objective of establishing the validity and reliability of the assessment due to dysergonomic exposure, taking into account factors of both pathological origin and the appearance of a clinical occupational picture (CCO). In graph 2, the different pathological factors present in the last 12 months are determined:

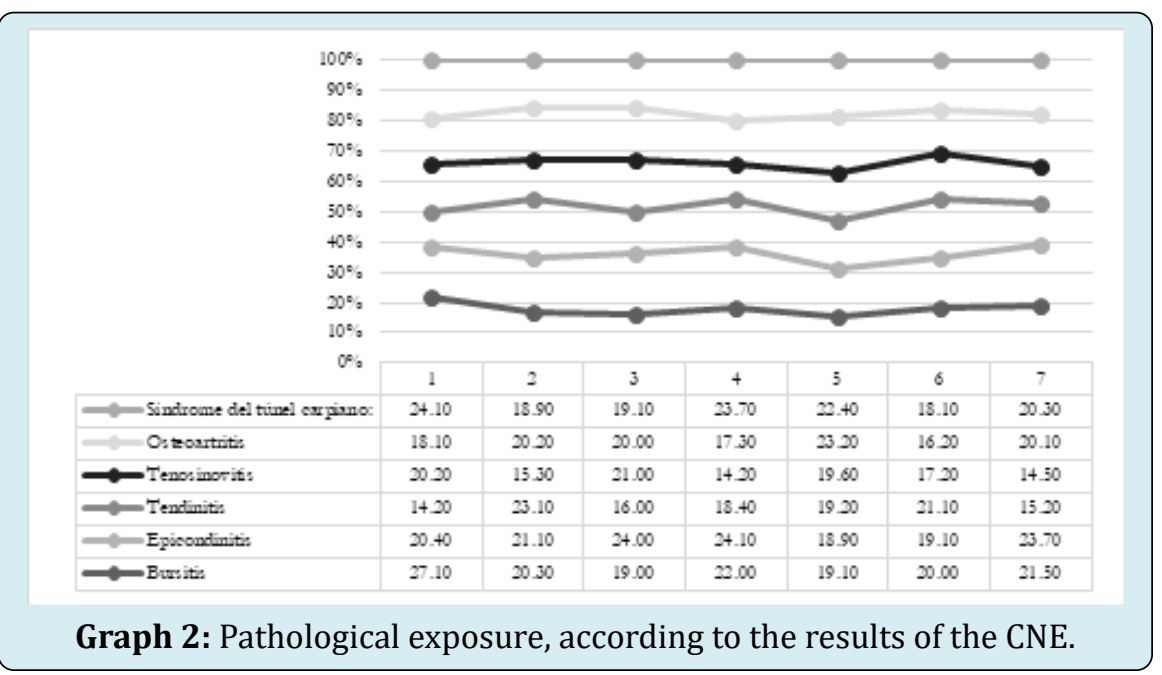

\section{OCRA Checklist Frequency}

are related to the representative MSDs in the operators:

In Figure 3 and graph 3, the Frequency by OCRA Checklist,

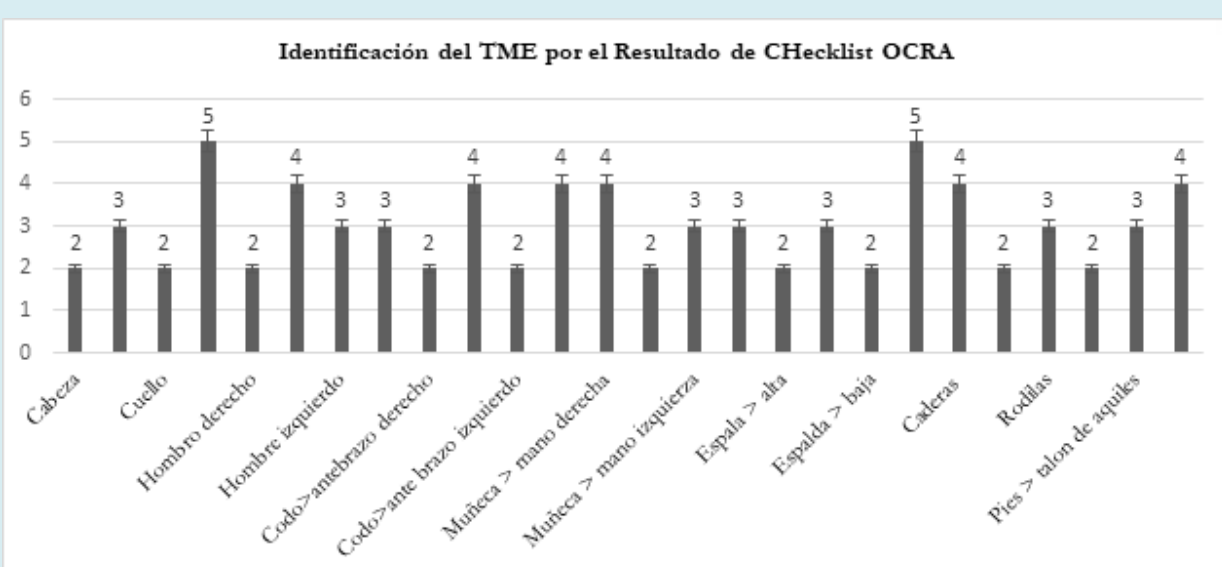

Graph 3: The identification of MSDs by the OCRA Checklist, determines the specific exposure risks in the operators, according to the work cycles in the last 14 days. The $\mathrm{CCO}$ of pain, represented high risk by postural biometry in: $5 \%$ of neck, $5 \%$ of lower back, while $4 \%$ as: discomfort in the right shoulder, elbow, forearm, right and left arm, hips and Achilles' heel, the estimate is a moderate risk [16-18]. 


\begin{tabular}{|c|c|c|}
\hline $\begin{array}{c}\text { Frecuencia Checklist } \\
\text { OCRA }\end{array}$ & Est. & *Valoración \\
\hline \multirow{2}{*}{ Cabeza } & $\mathrm{A}$ & 2 \\
\hline & $\mathrm{N}$ & 3 \\
\hline \multirow{2}{*}{ Cuello } & $\mathrm{A}$ & 2 \\
\hline & $\mathrm{N}$ & 5 \\
\hline \multirow{2}{*}{ Hombro derecho } & $\mathrm{A}$ & 2 \\
\hline & $\mathrm{N}$ & 4 \\
\hline \multirow{2}{*}{ Hombre izquierdo } & $\mathrm{A}$ & 3 \\
\hline & $\mathrm{N}$ & 3 \\
\hline \multirow{2}{*}{ Codo > antebrazo derecho } & $\mathrm{A}$ & 2 \\
\hline & $\mathrm{N}$ & 4 \\
\hline \multirow{2}{*}{ Codo $>$ ante brazo izquierdo } & $\mathrm{A}$ & 2 \\
\hline & $\mathrm{N}$ & 4 \\
\hline \multirow{2}{*}{ Muñeca $>$ mano derecha } & $\mathrm{A}$ & 4 \\
\hline & $\mathrm{N}$ & 2 \\
\hline \multirow{2}{*}{ Muñeca > mano izquierza } & $\mathrm{A}$ & 3 \\
\hline & $\mathrm{N}$ & 3 \\
\hline \multirow{2}{*}{ Espala > alta } & $\mathrm{A}$ & 2 \\
\hline & $\mathrm{N}$ & 3 \\
\hline \multirow{2}{*}{ Espalda > baja } & $\mathrm{A}$ & 2 \\
\hline & $\mathrm{N}$ & 5 \\
\hline \multirow{2}{*}{ Caderas } & $\mathrm{A}$ & 4 \\
\hline & $\mathrm{N}$ & 2 \\
\hline \multirow{2}{*}{ Rodilas } & $\mathrm{A}$ & 3 \\
\hline & $\mathrm{N}$ & 2 \\
\hline \multirow{2}{*}{ Pies $>$ talon de aquiles } & $\mathrm{A}$ & 3 \\
\hline & $\mathrm{N}$ & 4 \\
\hline
\end{tabular}

Figure 3: OCRA-CCO checklist results.

\section{Frequency of OCRA Analysis}

When determining the results of the measurement analysis, the 18 operational areas of the CPF are established in stages for both preventive action to the risk factor, in this way, the results are determined to the estimate, as presented in Table 4, where the score given the valuation of the OCRA method, However, in Table 4, the relationship between the consequences and the work cycles on the health exposure of the workers in the production plant will depend on the occupational medical actions of the company's occupational health and safety unit.

\begin{tabular}{|c|c|c|c|c|}
\hline OCRA Checklist Index & Risk Level OCRA Checklist & \multirow{2}{*}{ OCRA Method Level } & OCRA Exposure Index \\
\cline { 1 - 2 }$\leq 5$ & Optimal & \multirow{2}{*}{ No risk } & $\leq 1,5$ \\
\cline { 2 - 3 } & 5,1 a 7,5 & Acceptable & Very Low & 1,6 a 2,2 \\
\hline 7,5 a 11 & Uncertain & Lightweight & 2,3 a 3,5 \\
\hline 11,1 a 14 & Unacceptable Mild & High & 3,6 a 4,5 \\
\hline 14,1 a 22,5 & Unacceptable Medium & Very High & $>9$ \\
\hline
\end{tabular}

Table 4: Weighting and Hierarchy of the Checklist and OCRA method.

Based on the weighting and hierarchy of the risk index (RI) and as a disposition for the application to both preventive actions, starting from Very High Risk (VHR) to Very Low Risk
(VLR), these results start in relation to the OCRA Checklist shown in Figure 4. 


\begin{tabular}{|l|l|l|r|}
\hline \multicolumn{2}{|c|}{ Nombre Puesto } & Inaceptable Medio & IR \\
\hline 1 & Técnico de almacén & Inaceptable Alto & 16,75 \\
\hline 2 & Operador de generación & Inaceptable Alto & 32,25 \\
\hline 3 & Ayudante soldador api & Inaceptable Alto & 49 \\
\hline 4 & Técnico de instrumentación y control & Inaceptable Alto & 22,75 \\
\hline 5 & Técnico overhaul & Inaceptable Medio & 23,25 \\
\hline 6 & Técnico de mantenimiento & Inaceptable Medio & 20,75 \\
\hline 7 & Soldador & Inaceptable Alto & 22 \\
\hline 8 & Técnico eléctrico & Inaceptable Alto & 24,75 \\
\hline 9 & Técnico de mantenimiento automotriz & Inaceptable Medio & 22,75 \\
\hline 10 & Técnico de protección catódica & Inaceptable Alto & 14,75 \\
\hline 11 & Ayudante de recorrido derecho de vía & Inaceptable Alto & 37 \\
\hline 12 & Soldador api & Inaceptable Medio & 25,25 \\
\hline 13 & Operador de grúa & Inaceptable Alto & 21 \\
\hline 14 & Técnico de servicios auxiliares & Inaceptable Alto & 28,5 \\
\hline 15 & Técnico vacuum & Inaceptable Leve & 27,25 \\
\hline 16 & Técnico de laboratorio & Inaceptable Alto \\
\hline 17 & Operador de producción & Inaceptable Alto & 31,75 \\
\hline 18 & Técnico de campamentos & & 12,5 \\
\hline & & 24,25 \\
\hline
\end{tabular}

Figure 4: Results by IR.

With these results, the laboratory technician's work area has an unacceptable level of risk. Mild with an evaluation of 12.5 , according to the Checklist's risk index in an interval of 11.1 to 14 , in the area of the API welder's assistant, the risk level is unacceptably high with an evaluation of 49.0 , outside the $\mathrm{IE}^{22}$ range of $>22.5$.
In Graph 4, it shows the exposure assessment according to the OCRA Checklist, both in the upper extremities and in other workplaces. However, in the more OCRA-defined analysis, the exposure and work cycle consequences represent the lack of control in both upper and lower extremity movements.

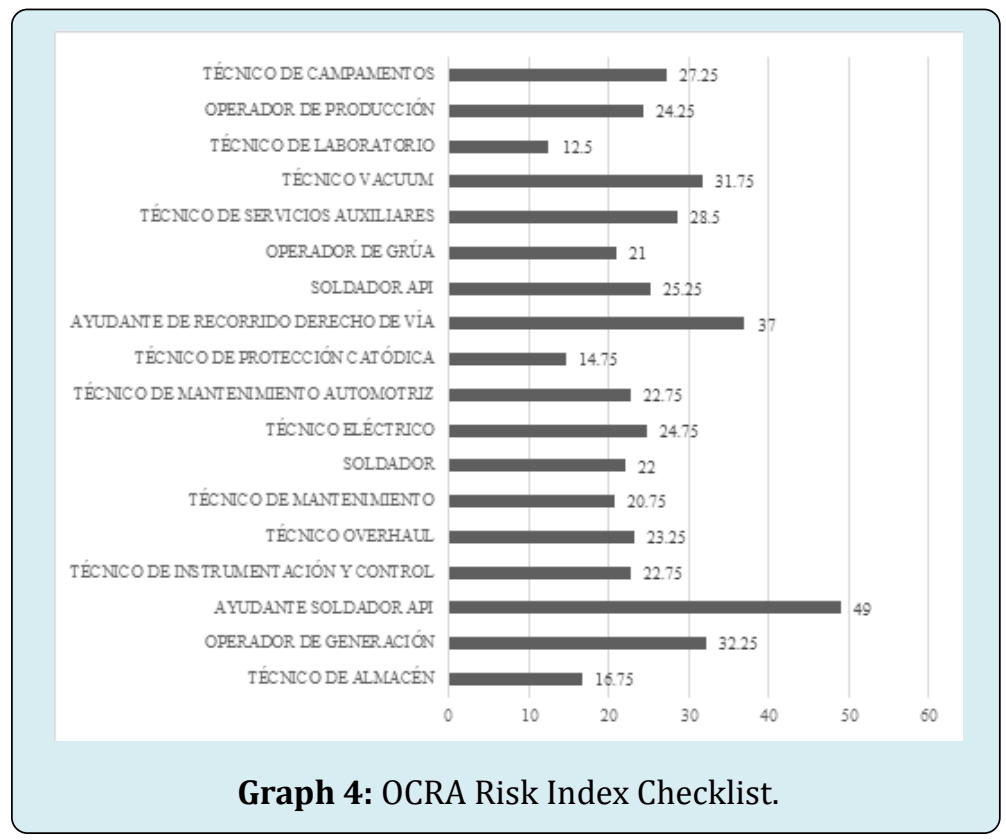

2 Index Exposure 
Once the analysis by the OCRA Checklist has been elaborated, we proceed to the methodological development of OCRA, which, allows us to make the VLTs for their exposure by cycles and rest breaks, these results in table 6 , allow us to reflect the operators with greater risk of exposure as in the case of the laboratory technician, with a level Without Risk of estimation to the IE of 1.34, for the right arm and 1.01, in the left arm. However, for the assistant on the right side of the road, the level is High Risk, with an estimated IE value of 5.11 , for the right arm and 3.47 for the left arm, in Table 5.

\begin{tabular}{|c|c|c|c|c|}
\hline \multirow{2}{*}{ No. } & \multirow{2}{*}{ Name Position } & \multirow{2}{*}{ Risk Level } & \multicolumn{2}{|c|}{ Risk Index OCRA Method } \\
\hline & & & BRH & B LH \\
\hline 1 & Warehouse Technician & Low Risk & 2,78 & 2,17 \\
\hline 2 & Generation operator & Low Risk & 3,29 & 1,29 \\
\hline 3 & Assistant welder api & High Risk & 3,71 & 2,16 \\
\hline 4 & Instrumentation and control technician & High Risk & 3,66 & 3,34 \\
\hline 5 & Technical overhaul & High Risk & 3,87 & 1,86 \\
\hline 6 & Maintenance Technician & High Risk & 3,52 & 3,3 \\
\hline 7 & Welder & High Risk & 4,4 & 2,67 \\
\hline 8 & Electrical Technician & High Risk & 3,86 & 2,24 \\
\hline 9 & Automotive Maintenance Technician & Low Risk & 2,64 & 1,43 \\
\hline 10 & Cathodic Protection Technician & High Risk & 4,65 & 1,88 \\
\hline 11 & Right-of-way assistant & High Risk & 5,11 & 3,47 \\
\hline 12 & Welder api & High Risk & 4,32 & 2,97 \\
\hline 13 & Crane operator & High Risk & 4,4 & 3,01 \\
\hline 14 & Auxiliary service technician & Low Risk & 3,3 & 2,1 \\
\hline 15 & Vacuum Technician & High Risk & 4,01 & 2,78 \\
\hline 16 & Laboratory Technician & No risk & 1,34 & 1,01 \\
\hline 17 & Production operator & High Risk & 4,76 & 3,05 \\
\hline 18 & Camp Technician & High Risk & 3,52 & 1,86 \\
\hline
\end{tabular}

Table 5: Analysis of OCRA Checklist and OCRA Method.

It is really an approach to the physiological context of the operator due to his/her exposure in each cycle of the task to be performed, that is, the variety of certain consequences both psychological and biological, which, when related, can produce an alteration to health, creating a BCC, disability or death. However, by insisting on a clinical-pathological or epidemiological approach to the solution of problems caused by MSDs or SCIs, in accordance with the results of the OCRA Method, the situation among the specific healthdisease aspects of the operators is analyzed, identifying their difficulties during or after each cycle. Therefore, to establish the measurement of these factors of dysergonomic risks by MSD, they are prioritized and hierarchized, as a previous step to achieve the fundamental purpose of the preventions to the health, that allows us to improve with specific measures and determined terms, to the state of health of all the operators; in the table 6, (elaborated in the laboratory of $\mathrm{EHO}^{3}-\mathrm{UTN}^{4}$ $03 / 2020$ ), the most frequent pathologies with form to the $\mathrm{TLV}^{5}$ are defined.

In Figure 4, the clinical pathology or epidemiological table by Occupational Risk Factor (ORP) of symptoms due to pain in the body, and based on the analysis of the Nordic Questionnaire (NC) and its Clinical Functional Assessment (CFA), the estimate by case of pathologies or clinical picture due to pain, is personified in the last 14 days $(n=150)$.

\footnotetext{
3 Ergonomics and Occupational Hygiene

4 Northern Technical University

5 Threshold Limit Values (TLV)
} 


\begin{tabular}{|c|c|c|c|c|}
\hline Pathologies & FRO & CN & ECF & Average n= \\
\hline Subacromial bursitis & 83,5 & 93,8 & 79,2 & 92,3 \\
\hline Tendinitis & 93,2 & 99,3 & 77,2 & 81,2 \\
\hline Rotator cuff conditions & 92,3 & 97,4 & 71,3 & 91,4 \\
\hline Cervical sprain & 8,9 & 81,8 & 73,2 & 73,8 \\
\hline Cervical Tension Syndrome & 63,5 & 93,2 & 62,0 & 58,7 \\
\hline Cervical Spondylosis & 93,2 & 92,3 & 79,2 & 91,4 \\
\hline Herniated disc & 52,3 & 78,9 & 77,2 & 73,8 \\
\hline Sciatica & 78,9 & 91,4 & 71,3 & 58,7 \\
\hline Knee Arthritis & 83,5 & 93,2 & 73,2 & 61,3 \\
\hline Bursitis & 49,2 & 92,3 & 62,0 & 73,2 \\
\hline Patellar Tendinitis & 79,2 & 88,9 & 71,8 & 87,0 \\
\hline Muscle strain & 77,2 & 93,2 & 93,2 & 81,4 \\
\hline Trapezium contracture & 71,3 & 87,0 & 92,3 & 59,9 \\
\hline Stenosing tenosynovitis & 73,2 & 81,4 & 78,9 & 52,3 \\
\hline Cross-over or intersection syndrome & 62,0 & 97,4 & 63,5 & 78,9 \\
\hline Spring Finger & 93,2 & 81,8 & 93,2 & 83,5 \\
\hline Carpal Tunnel Syndrome & 91,1 & 93,2 & 52,3 & 49,2 \\
\hline Epicondylitis & 82,3 & 92,3 & 78,9 & 78,9 \\
\hline Vibration Syndrome (SVES) & 53,9 & 78,9 & 83,5 & 63,5 \\
\hline
\end{tabular}

Table 6: Clinical and occupational pathology tables, according to OCRA Method assessment results.

\section{Conclusion}

By preventing occupational pathologies derived from dysergonomic risk, we are immersed in several factors of applied ergonomics, such as postural biometry or biomechanics of the human body in work cycles. However, in the present research study carried out on operators of crude oil production plants or so-called CPFs, where the continuous times of 14 days are rotated by 14 by 14, divided into 7-day day shifts and 7-night shifts. Therefore, the frequencies of pathological cases due to pain or musculoskeletal disorders derived from work reflected segments such as: low back pain (lumbago) with $38.2 \%$, rotator cuff syndrome or shoulder injury (Bursitis) with $21.6 \%$, right arm injuries (Tendinitis) with $14.4 \%$, neck pain (Cervicalgia) with $12.8 \%$ and wrist pain (carpal tunnel syndrome) with $13.0 \%$.

Finally, firstly, to implement an Occupational Health program with emphasis on postural ergonomics and, in relation to repetitive movements in each cycle of tasks to be performed, as well as, to establish active pauses, rotation and prolonged breaks in accordance with the time of exposure. Secondly; to establish specific occupational medical examinations, of X-rays of the spine, shoulders and wrist. Thirdly, to follow up preventive medicine for the most frequent operators of chronic pathologies.

\section{References}

1. Jan de Kok PV (2019) Work-related MSDs: prevalence, costs and demographics in the EU. European Agency for Safety and Health at Work - EU-OSHA, Luxembourg.

2. Alvarez-Casado E (2009) Risk Assessment Manual for the Prevention of Musculoskeletal Disorders. Factors Humans, Barcelona, Spain.

3. Vélez MZ (2013) Ergonomics and Safety Manual. Alfaomega Colombla SA, Bogotá.

4. Vélez MZ (2018) Ergonomics and Safety Manual II. Alfaomega-Colombia, Bogotá.

5. Veau BL (2008) Biomechanics of the Human Movement. Trillas, Mexico.

6. LMA (2016) Disergonomic risks due to physical load in underground mining works and the improvement of the health and safety of workers. Research Institute of the Faculty of Geological, Mining, Metallurgical and Geographic Engineering, pp: 77-83. 
7. Díaz JM (2018) Safety and health in the workplace. Tébar Flores, Madrid 11a: 144-145.

8. Martinez MM (2017) Validation of the Standardized Nordic Questionnaire of Musculoskeletal Symptoms for the Chilean Working Population, Adding a Scale of Pain. Public Health Journal 21(2): 41-51.

9. ANCAP (2019) Refinery Processes.

10. Standardization IO (2019) NTE/ISO 11228-3:2019. IQNet Association-The International Certification Network, Bern, Switzerland.

11. José DA (2019) Risk assessment of repetitive movements using the Check List Ocra. Universidad Politécnica de Valencia, Ergonautas, Span.

12. Pellicer LL (2015) Manual of Ergonomics Applied to the Prevention of Occupational Risks. Pyramid, Mdrid, pp: 126-127.
13. Castillo-Martínez J (2017) The evaluation of repeated movements in the upper limb The OCRA method. Revista Colombiana de Rehabilitación ER, Bogotá.

14. Picazo Antonio R (2003) NTP 629: Repetitive movements: evaluation methods OCRA Method: update. Instituto de Nacional de Seguridad e Higeine en el Trabajo.

15. Ergosoft Pro (2018) Psycho-prevention Technology and Prevention.

16. Diego, Antonio J (2019) Risk assessment of repetitive movements using the Check List Ocra. Ergonautas, Universidad Politécnica de Valencia, Spain.

17. Francisco A Sanchez (2007) The Genesis of MSDs: a New Way of Analysis. Ergonomics and Psychocology, pp: 2130.

18. Fuentelsaz Gallego C (2004) Sample size calculation. Matronas Profesión, pp: 5-13. 